\title{
O CLIMA URBANO - NATUREZA, ESCALAS DE ANÁLISE E APLICABILIDADE
}

\author{
HENRIQUE ANDRADE ${ }^{1}$
}

\begin{abstract}
Resumo - A climatologia urbana tem hoje um carácter pluridisciplinar, sendo extremamente importante a contribuição dada pelos geógrafos. O clima é uma componente do ambiente urbano, resultando da interacção entre factores naturais e antrópicos. Um aspecto central na compreensão dos fenómenos climáticos urbanos é o das suas escalas, espacial e temporal, considerando-se necessário definir conceitos e terminologias. Analisam-se os conceitos de microescala, escala local e mesoescala. São abordados alguns aspectos da aplicação da climatologia ao planeamento urbano. A análise da forma como a climatologia urbana se articula com outras áreas de estudo do ambiente urbano mostra que essa articulação é, em geral, insuficiente, quer pela incapacidade dos climatólogos de integrar o seu trabalho numa perspectiva ambiental mais ampla, quer pela reduzida importância dada às temáticas ambientais nas abordagens sociológicas e económicas do espaço urbano. Salienta-se a importância da contribuição da climatologia urbana para a qualidade de vida e para a sustentabilidade urbana. É dada particular atenção aos aspectos bioclimáticos, que condicionam o conforto e a saúde das populações e, indirectamente, o consumo de energia para climatização, sendo discutidos alguns modelos bioclimáticos. É referida a necessidade de uma abordagem «adaptativa», embora se verifique que os instrumentos para o desenvolvimento desse tipo de modelo não tenham sido, ainda, definidos. Por fim, discute-se a intervenção da Climatologia no Planeamento a diferentes escalas, desde a regional até à de edifícios individuais e salienta-se a importância de a climatologia contribuir para a definição dos modelos urbanos sustentáveis.
\end{abstract}

Palavras-chave: Clima urbano, ambiente urbano, escalas climáticas, aplicação, planeamento, forma urbana.

\begin{abstract}
The URBAN CLIMATE - NATURE, SCALES OF ANALYSIS AND APPLICABILITY. Urban climatology is today multidisciplinary in nature, and geographers' contributions to the field are extremely important. The climate is a component of the urban environment, resulting from the interaction between natural and human factors. Central to understanding urban climatic phenomena is its spatial and temporal scale. It is therefore necessary to define the concepts and terminology pertinent to this domain. The concepts of microscale, local scale and mesoscale are analysed here as well as some features of the application of climatology to urban planning. The analysis of the way in which urban climatology is linked to other areas of urban environmental studies shows that this linkage is generally insufficient, whether due to climatologists' inability
\end{abstract}

1 Professor Auxiliar da Faculdade de Letras da Universidade de Lisboa. Investigador do Centro de Estudos Geográficos. E-mail: handrade@fl.ul.pt 
to integrate their work into a broader environmental perspective or due to the little importance given to environmental topics in sociological and economic work on urban space. The importance of the contribution of urban climatology to the quality of life and urban sustainability is emphasised. Particular attention is paid to bioclimatic aspects that condition people's comfort and health and, indirectly, energy consumption related to air conditioning, and some bioclimatic models are discussed. The need for an «adaptive» approach is highlighted, though instruments for the development of this type of model have not yet been defined. The intervention of climatology in planning at different scales - from the regional scale to the individual building - is discussed and the importance of climatology's contribution to the definition of sustainable urban models reinforced.

Key words: Urban climate, urban environment, climatic scales, application, planning, urban form.

Résumé - LE CLIMAT URBAIN: NATURE, ÉCHELLES D'ANALYSE ET POSSIBILITÉS D'APPLICATION. La climatologie urbaine a désormais un caractère pluridisciplinaire mais la contribution des géographes demeure très importante. Le climat est une composante du milieu urbain où interfèrent des facteurs naturels et humains. L'échelle temporelle et spatiale d'analyse est essentielle et il est nécessaire de définir à cet égard les concepts et la terminologie employés (micro-échelle, échelle locale et méso-échelle). Certains aspects de l'application de la climatologie à la planification urbaine sont ensuite abordés. On considère l'articulation, en général insuffisante, de la climatologie avec les autres aires d'étude du milieu urbain. Les aspects bioclimatiques sont particulièrement importants parce qu'ils conditionnent le confort et la santé de la population et, indirectement, la consommation d'énergie. Quelques modèles bioclimatiques sont discutés et on souligne l'intérêt qu'auraient des modèles adaptatifs, bien qu'on doive reconnaître que les instruments qui permettraient leur développement ne sont pas encore définis. On discute la place que la climatologie occupe dans la planification, de l'échelle régionale jusqu'à celle des édifices isolés, et on indique son importance pour la définition de modèles urbains durables.

Mots-clés: Climat urbain, milieu urbain, application, planification, forme urbaine.

\section{INTRODUÇÃO}

As cidades são sistemas complexos, abertos a fluxos de energia e massa e caracterizados por um contínuo processo de mudança (DOUGLAS, 1983; LAWRENCE, 2003; UEMRI, Internet $^{2}$; CCE, 2004). A importância crescente das áreas urbanas, em termos demográficos ${ }^{3}$, socio-económicos e culturais (CCE, 1990; BREHENY, 1992), faz com que os seus problemas ambientais sejam, cada vez mais, uma prioridade dos poderes públicos (BREHENY, 1992) e um tema central de investigação em diferentes áreas científicas (PARTIDÁRIO, 2001; KAMP et al., 2003; PAccione, 1990, 2003; STEEMERS, 2003a).

2 http://www.gdrc.org/uem/doc-intro.html

3 Segundo a Divisão de População da Organização das Nações Unidas (Word Urbanization prospects: the 1999 revision - divulgado na Internet), as áreas urbanas concentravam, em 2000, $47 \%$ da população mundial, devendo atingir os $50 \%$ em 2007 e os $60 \%$ em 2030. Em 2000, 4,3\% da população mundial vivia em aglomerações com 10 milhões de habitantes ou mais, prevendo-se que essa percentagem atinja 5,2\% em 2015; em contrapartida, nessa data, $25 \%$ da população mundial deverá viver em pequenas cidades (menos de 500000 habitantes). 
Neste artigo, elaborado na sequência de uma tese de climatologia urbana (ANDRADE, 2003), é feita uma síntese bibliográfica, não exaustiva, sobre diferentes aspectos da climatologia urbana e sobre a forma como esta disciplina se articula no contexto dos estudos sobre ambiente urbano. Na parte I é abordada a natureza do clima urbano e as suas escalas espacial e temporal. Na parte II é tratada a aplicabilidade da climatologia urbana no planeamento, a diferentes escalas, e a sua articulação com outras áreas de estudo do ambiente urbano, sendo salientada a importância da climatologia para a definição dos modelos urbanos sustentáveis.

O ambiente urbano engloba componentes naturais, construídas, económicas e sociais, podendo ser abordado segundo pontos de vista muito diversos. O 'ambiente físico’ corresponde, segundo RAU e WotTEN (1980, citados por PARTIDÁRIO, 2001) aos elementos naturais e construídos, enquanto KNOX (1987), reduz as 'qualidades físicas do ambiente urbano' aos aspectos morfológicos do espaço construído. Embora PARTIDÁRIO (2001) saliente as vantagens de uma abordagem 'integrada' dos problemas urbanos, a divisão tradicional em componentes 'físicas e humanas' é, claramente, dominante. LAWRENCE (2003) defende uma abordagem integrada, no âmbito da ecologia humana, definida, por este autor, como o estudo das interacções dinâmicas entre as populações e as características físicas, bióticas, sociais e culturais do seu ambiente.

Encarando o espaço urbano como um ecossistema (Douglas, 1983; NEWMAN, 1999; LAWRENCE, 2003), as condições atmosféricas integram-se no conjunto de factores abióticos os quais, interagindo com outros factores (bióticos e socio-culturais), condicionam a população humana. NEWMAN (1999) analisa o sistema urbano como uma extensão do modelo metabólico (fig. 1).

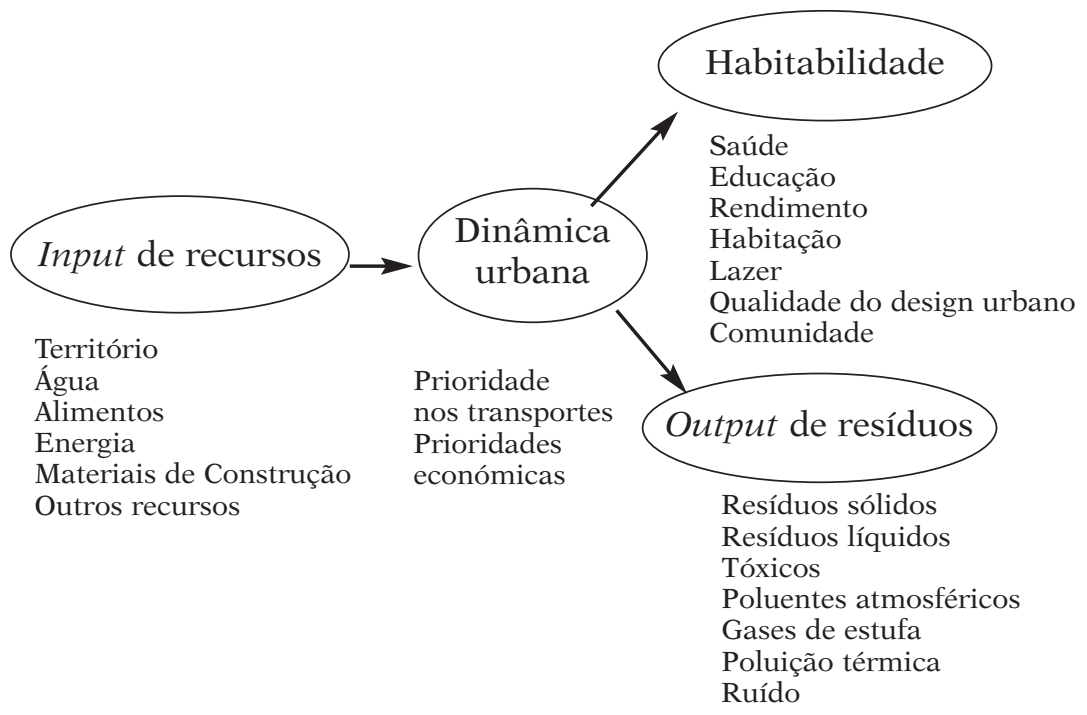

Fig. 1 - Modelo metabólico do espaço urbano (segundo Newman, 1999)

Fig. 1 - Metabolic model of the urban space (according to NEWMAN, 1999) 


\section{NATUREZA E ESCALAS DO CLIMA URBANO}

\section{A natureza do clima urbano}

OKE (1984b: 19) definiu meteorologia urbana como o «estudo dos processos físicos, químicos e biológicos que operam para mudar o estado da atmosfera nas cidades» e climatologia urbana como o "estudo dos seus estados atmosféricos mais frequentes». A AMS define, simplesmente, o clima urbano como «the climate affected by the presence of a town or city».

O clima urbano resulta das modificações que as superfícies, materiais e as actividades das áreas urbanas provocam nos balanços de energia, massa e movimento (LANDSBERG, 1981; OKe, 1987; 1988; KutTler, 1988 e ARNFIELD, 2003).

LOWRY (1977) expressou a natureza do clima urbano através da equação:

$$
M, i, t, x=C, i, t, x+L, i, t, x+U, i, t, x
$$

Em que $(M)$ é o valor assumido por uma dada variável climática, no local urbano $x$, no momento $t$ e com o tipo de tempo $i,(C)$ é a componente regional, $(L)$ a componente local devida aos elementos não urbanos, como o relevo, e $(U)$ a componente urbana propriamente dita. Ou seja, o clima urbano resulta da interacção dos factores urbanos com o clima regional e com o meio físico pré existente.

A climatologia urbana é uma área de intensa interdisciplinaridade, onde se 'cruzam’ contribuições de especialistas de diferentes domínios, como a Geografia, a Arquitectura e o Urbanismo, a Engenharia e a Meteorologia (LAWRENCE, 2003). Trata-se de um domínio científico onde é tradicionalmente importante a intervenção dos geógrafos (de que o exemplo mais saliente é OKE, da Universidade de Vancouver). Destacam-se em Portugal os estudos iniciados por M. J. AlcoforAdo, há cerca de vinte anos, sobre o clima de Lisboa (AlcoforAdo, 1987, 1991, 1992, 1995 e 1996) e prosseguidos no Centro de Estudos Geográficos (ANDrade e Lopes, 1998; Andrade, 1998a e b, 2000, 2003; AlcoFORADO et al., 1998 e 1999; AlCOFORADO e ANDRADE, 2005; Lopes, 1994, 1995, 1996, 1998 e 2003; Lopes e VieIRA, 2001; VieIRA e VASCONCELOS, 2003). Num âmbito e escala diferentes, podem ser indicados Saraiva (1996), Cadima (2000), Gonçalves et al. (2004), Deus (2004) e Neto (2005). Outros investigadores desenvolveram trabalhos de climatologia urbana noutras cidades portuguesas, como Monteiro (1993) e Góis (2002), no Porto; GanHo (1996 e 1998) em Coimbra; Katzchner et al. (1999) em Bragança; Alcoforado e TABORdA (1997), em Évora, e Pinho e Orgaz (2000), em Aveiro.

Contudo, embora de acordo com KNOx (1987: 20), "the study of the physical qualities of the urban environment is one of the long established branches of urban geography», a integração entre as abordagens 'física e humana' do ambiente urbano tem sido difícil, o que foi já notado por Douglas (1987); a julgar pela bibliografia consultada, essa integração não tem evoluído de forma substancial. Esse facto evidencia alguma incapacidade dos 'climatólogos urbanos' de integrar o seu trabalho numa perspectiva mais ampla do ambiente urbano. Por outro lado, essa falta de contacto reflecte a insuficiente integração da temática ambiental nas abordagens sociológicas e económicas do espaço urbano (LAWRENCE, 2003). 


\section{Escalas espaciais do clima urbano}

Verifica-se, na bibliografia consultada sobre ambiente urbano, que o reconhecimento das características específicas do clima das cidades se encontra, aparentemente, generalizado; pelo contrário, é relativamente confusa a compreensão, por um lado, da forma como o clima urbano se articula com o clima regional e, por outro, da 'estrutura interna' dos próprios climas urbanos. A utilização generalizada (e incorrecta) do termo 'microclima' para designar qualquer particularidade climática do espaço urbano revela esse facto. A existência de divisões verticais na atmosfera urbana é, ainda, de apreensão mais difícil.

A necessidade de dispor de um corpo de conceitos e de uma terminologia simples levou à distinção de categorias espaciais discretas, sempre arbitrárias e artificiais, pois os fenómenos atmosféricos são, por natureza, contínuos (OKE, 1987). ORLANSKY (1975) distinguiu (fig. 3) os fenómenos de microescala (dimensão típica até $2 \mathrm{~km}$ de extensão), mesoescala (2 a $2000 \mathrm{~km}$ ) e macroescala (>2 000km). WANNER e FILLIGER (1989) consideram que os fenómenos urbanos se restringem ao espaço e tempo que medeia entre a microescala (para os elementos individuais) e a mesoescala, para grandes áreas metropolitanas. Segundo Moran e PorTelli (1987) os fenómenos urbanos típicos integram-se na mesoescala e MATZARAKIS (2001) considera que essa é a dimensão característica da ilha de calor urbano.

\section{Clima regional: determina as condições climáticas gerais}

\section{Mesosclima urbano}

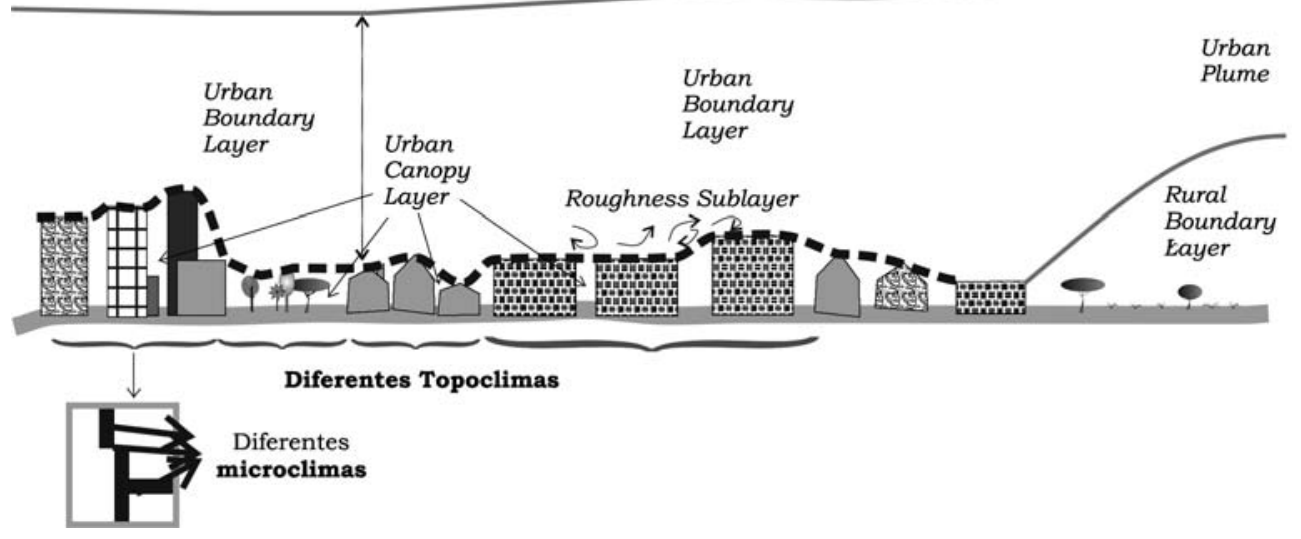

Fig. 2 - Estratificação vertical da atmosfera urbana e escalas de análise Fig. 2 - Vertical stratification of the urban atmosphere and scales of analysis

A divisão vertical da atmosfera urbana divulgada por OKE (1984b, 1987 e 2004) é hoje largamente adoptada (fig. 2). Abaixo da superfície activa urbana (correspondente, grosseiramente, ao nível dos telhados dos edifícios; OKE, 1984b e 1987), o volume de ar entre os edifícios é a Urban Canopy Layer (UCL; atmosfera urbana inferior - ALCOFORADO, 1992) fortemente afectada pelas condições envolventes. Acima da superfície activa distingue-se a Urban Boundary Layer (UBL; atmosfera urbana superior) que integra a 


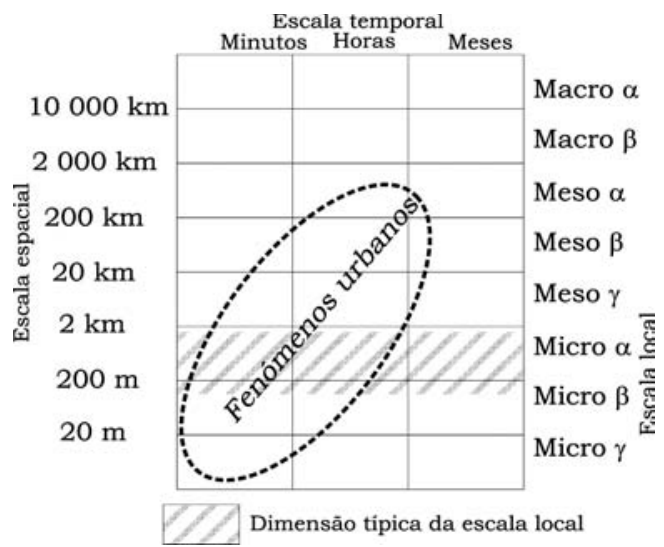

Fig. 3 - Dimensões espacial e temporal típicas dos processos atmosféricos, (segundo ORLANSKY, 1975) e área relevante para os fenómenos urbanos (segundo WANNER e FILLIGER, 1989)

Fig. 3 -Common spatial and temporal dimension of atmospheric processes, (according to ORLANSKY, 1975) and the area under consideration for urban phenomena (according to WANNER and FILLIGER, 1989)

influência térmica de toda a cidade, podendo estender-se para sotavento da área urbana, formando a chamada 'pluma urbana'. A camada inferior da UBL é a Roughness Sublayer, sector onde o fluxo é influenciado pela rugosidade dos elementos individuais (STULL, 1988; RоTACH, 1999).

As designações topoclima e clima local surgem, com muita frequência, na literatura (Yoshino, 1975; LAndsberg, 1981; Wanner, 1984; Choisnel, 1984; OKe, 1984 b e 1987; AlcoforAdo, 1992 e 1999), tendendo actualmente a ser considerados sinónimos; Alcoforado (1992) salienta que topos significa local, pelo que os dois termos são equivalentes. Sobretudo na bibliografia de origem geográfica, topoclima e clima local generalizaram-se para designar o clima de áreas homogéneas quanto à ocupação do solo ou condições topográficas. As dimensões típicas do topoclima variam muito, de acordo com os diferentes autores: segundo SCHERER et al. (1999), o topoclima abrange áreas entre algumas dezenas e algumas centenas de metros, correspondendo portanto, em parte, aos microclimas $\beta$ e $\gamma$ na figura 3 .

Num estudo sobre o clima de um parque urbano, SpronkEn-Smith et al. (2000) distinguiram claramente as três escalas referidas: a diferenciação entre o parque e a área urbana envolvente corresponde à escala local; os factores exteriores ao parque têm um carácter de mesoescala, enquanto a diferenciação térmica no interior do espaço verde é de microescala.

Em ANDRADE (2003) procurou definir-se de uma forma mais precisa os conceitos referidos; foram indicadas 'dimensões típicas' para cada uma das categorias, sem adoptar limites rígidos para essas dimensões (fig. 3):

- Microclima - reflecte a influência de elementos urbanos individuais e dos seus arranjos mais elementares (edifícios e as suas partes constituintes; ruas e praças, pequenos jardins); a dimensão típica pode ir até cerca de uma centena de metros; a influência directa desses elementos restringe-se à Urban Canopy Layer. 
- Clima local - clima de uma área com uma combinação característica de elementos (ScHERER et al., 1999), podendo corresponder seja a um tipo de ocupação do solo diferenciado (bairro, parque urbano), seja a condições topográficas específicas (vale, colina, etc.). Um clima local engloba um mosaico de microclimas, que se repetem com alguma regularidade (OKE, 1997 e 2004) e, idealmente, corresponde a uma 'unidade climo-topológica' (AlCOFORADO, 1999).

- Mesoclima - corresponde à influência integrada da cidade (compreendendo vários climas locais), essencialmente ao nível da Urban Boundary Layer. Podem considerar-se igualmente como efeitos de mesoescala os efeitos 'extra urbanos', de dimensão aproximada ou superior à da própria cidade (sistemas de brisas, barreiras topográficas, etc.). Não se pode deixar de relembrar que o clima urbano depende dos fenómenos de escala climática superior (mesoescala $\beta$ e $\alpha$, macroescala).

\section{Escala temporal em climatologia urbana}

Na equação de LowRY (1977), anteriormente referida, o clima urbano varia no quadro do tipo de tempo (i), o qual é determinado em primeiro lugar por factores de escala sinóptica. O tipo de tempo condiciona a variação espacial dos elementos climáticos no espaço urbano, sobretudo através do vento, da nebulosidade e da estabilidade vertical da atmosfera (LANDSBERG, 1981; OKE, 1987; Ellasson e Svenson, 2002; Svenson e Eliasson, 2002). A regra geral é de que, sob fluxo sinóptico forte, as diferenças locais são, em grande parte, suprimidas e, com vento fraco e céu limpo, os efeitos locais e microclimáticos controlam as condições climáticas da camada inferior da atmosfera (LANDSBERG, 1981). Esta relação tem condicionado toda a investigação em climatologia urbana, o que resultou num conhecimento reduzido do clima urbano sob a sequência habitual de situações sinópticas (MoRRIs e SimmondS, 2000), dando origem a uma imagem 'distorcida' e de difícil aplicação do clima urbano (Mills, 1999; Eliasson e SVENSSON, 2002).

O facto de a mesma estrutura urbana poder 'responder', de formas muito diversas, sob diferentes tipos de tempo é uma habitual fonte de dificuldade na passagem para a aplicação. O conhecimento das características dos diferentes tipos de tempo, da sua frequência sazonal e das suas interacções com as estruturas urbanas é, portanto, um aspecto fundamental a considerar em Climatologia aplicada.

Na mesma equação de LowRY, uma determinada condição climática urbana refere-se a um dado $(t)$ momento. Portanto a estacionaridade ${ }^{4}$ do clima, a uma escala superior, é também um factor do clima urbano. A variabilidade climática (nomeadamente o tema do global change, hoje quase 'hegemónico’ em certas áreas), pode ser também analisada do ponto de vista urbano, sob duas perspectivas diferentes (frequentemente confundidas):

1. A influência das áreas urbanas sobre a mudança climática 5;

2. As consequências da mudança climática sobre o ambiente urbano.

4 Segundo WiLKS (1995), uma série é estacionária quando a sua média e a sua autocorrelação se mantêm constantes ao longo do tempo.

5 As áreas urbanas contribuem com cerca de $78 \%$ das emissões de gases com efeito de estufa, à escala global; a esse efeito, deve-se juntar a redução da capacidade de fixação de $\mathrm{CO}_{2}$ nos ecossistemas florestais, devido à procura de madeira. 
As consequências previsíveis da mudança climática global sobre o clima urbano são muito incertas, dependendo de interacções complexas e a diferentes níveis, que podem ter resultados contraditórios e regionalmente diferenciados: por exemplo, uma diminuição do uso de aquecimento doméstico pode reduzir a componente antrópica do aquecimento urbano, enquanto um incremento da frequência de tipos de tempo estáveis pode ter um efeito contrário (OKE, 1997). Contudo, o aquecimento global é a priori apresentado como negativo para os espaços urbanos, devido às suas consequências térmicas sobre a qualidade do ar e da água, a frequência dos fenómenos extremos e a possível subida do nível médio do mar (PATz et al. 2000). Epstein e Rogers (2004) discutem os efeitos combinados do incremento da concentração de poluentes na atmosfera e da mudança climática, nas áreas urbanas (fig. 4), segundo estes autores «...a combinação de poluentes atmosféricos, aeroalergéneos, vagas de calor e massas de ar pouco saudáveis, crescentemente associadas com a mudança climática, causa danos no sistema respiratório, particularmente para crianças em crescimento e esses impactes afectam de forma desproporcionada os grupos minoritários no interior das cidades...»; RoGERS (2004) salienta os impactes do aumento da concentração de $\mathrm{CO}_{2}$ (independentemente dos efeitos térmicos) na produção de pólen e desenvolvimento de fungos, com efeitos negativos sobre a saúde.

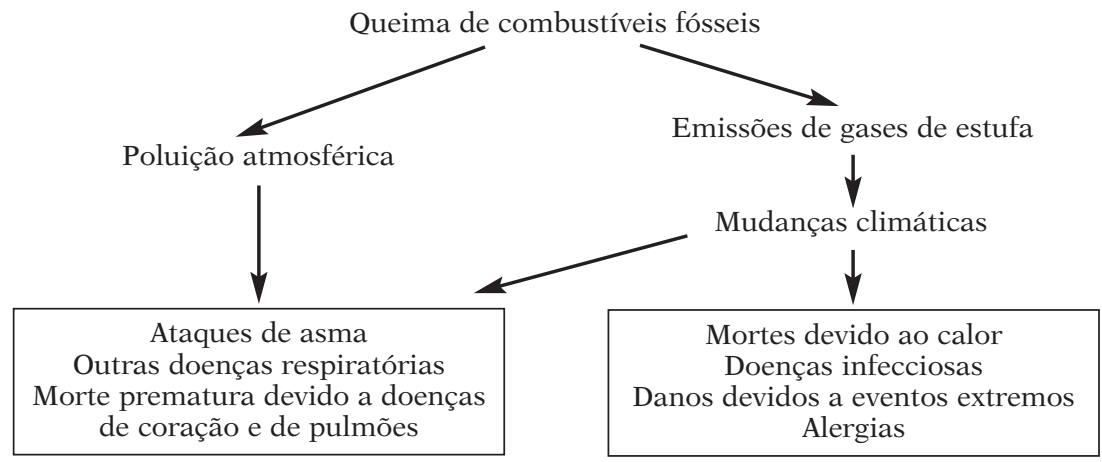

Baseado em EPSTEIN e Rogers (2004)

Fig. 4 - Impactes dos combustíveis fósseis sobre a saúde Fig. 4 - Impacts of fossil fuels on health

Nas publicações da Comunidade Europeia sobre ambiente urbano (nomeadamente CCE, 1990; GPAU, 1996; CCE, 2004), as principais referências às interacções entre o clima e o espaço urbano dizem respeito à variabilidade climática: a CCE (2004) salienta nomeadamente a participação europeia na campanha Cities for Climate Protection, da ICLEI, que visa o desenvolvimento de uma agenda estratégica para redução dos gases com efeito de estufa (www.iclei.org/CO2). Por outro lado, recomenda-se que os estados membros avaliem «... as consequências das alterações climáticas para as suas cidades, de modo a que não sejam iniciadas urbanizações inadequadas e que as adaptações a novas condições climáticas possam ser incorporadas no processo de ordenamento do território...»(CCE, 2004: 32). 


\section{APLICABILIDADE DA CLIMATOLOGIA URBANA}

\section{Algumas questões conceptuais}

A aplicação da Climatologia no Planeamento das áreas urbanas é um objectivo apontado por quase todos os autores; a constatação da falta de aplicação é também muito frequente. É, em geral, referida a adequação climática dos modelos urbanos e arquitectónicos tradicionais (OLGYAY, 1963; BRAZEL e MARTIN, 1997; GOLANY, 1996; Givoni, 1998; Mills, 1999; Eliasson, 2000), em contraste com a prática actual do desenho urbano, caracterizado pela pouca ou nenhuma atenção dada às condições ambientais (GolanY, 1996). Contudo, segundo RATTI et al. (2003), muitas das apreciações sobre a adequação climática dos modelos tradicionais são vagas e baseadas em observações isoladas, qualitativas e de senso comum.

O recurso a soluções tecnológicas, com um consumo crescente de energia e impactes ambientais acentuados, entra em contradição evidente com os actuais paradigmas da sustentabilidade urbana (Auliciems e DE Dear, 1997; CAdima, 2000; SANTAMOURIS, 2001a; STEEMERS, 2003a).

Os problemas do ambiente urbano (e a sua componente climática) são frequentemente encarados sob duas perspectivas diferentes (BREHENY, 1992):

a. O consumo e degradação de recursos externos à cidade;

b. A qualidade de vida no espaço urbano.

A primeira perspectiva tem a ver sobretudo com o consumo de água, energia e outros recursos e com a produção de resíduos (do ponto de vista climático, é particularmente relevante a emissão de poluentes atmosféricos - OKE, 1997; PoEIRA et al., 1999). WHITFORD et al. (2001) identificam, como principais áreas de impacte da urbanização sobre o ambiente, o clima, a hidrologia, a produção de $\mathrm{CO}_{2}$ e a biodiversidade, considerando que o incremento da sustentabilidade passa pela redução dos impactes urbanos, em todos estes domínios, quer ao nível externo (regional e global), quer da qualidade de vida no espaço urbano.

A qualidade de vida é um conceito central no Planeamento urbano sendo definida, de forma muito simples, por DiENER e SuH (1996, cit. por KAMP et al., 2003) como 'a satisfação com a vida'; KAMP et al. (2003) consideram que a qualidade de vida resulta do ajustamento pessoal entre um conjunto de domínios humanos (económicos, pessoais, etc.) e ambientais (destacados na figura 5), englobando nestes últimos o ambiente natural (e, explicitamente, o clima) e aspectos como o ambiente construído, os recursos naturais e a segurança, onde se integra a componente climática (fig. 5).

O clima urbano deve assim ser considerado enquanto componente de qualidade do ambiente e, portanto, de contribuição para a qualidade de vida no meio urbano. Ao considerar a segurança, enquanto componente da qualidade de vida, aborda-se outra área de intervenção tradicional da geografia física: a dos riscos naturais (DougLAS, 1983 e 1987; Paccione, 1990; Mitchell, 1998). Contudo, a articulação entre as duas perspectivas - qualidade de vida/riscos naturais - nem sempre foi fácil. PARTIDÁRIO (2001) apresenta a questão em termos de limiar: a ultrapassagem de determinada magnitude de um dado fenómeno desencadeia as situações de risco; valores inferiores ao 'limiar de risco' não são necessariamente inócuos, podendo gerar, pelo menos, condições de desconforto.

A identificação dos riscos naturais de origem climática tem variado: DougLAS (1983) refere os riscos de carácter hidrológico, os ventos fortes, os incêndios florestais 


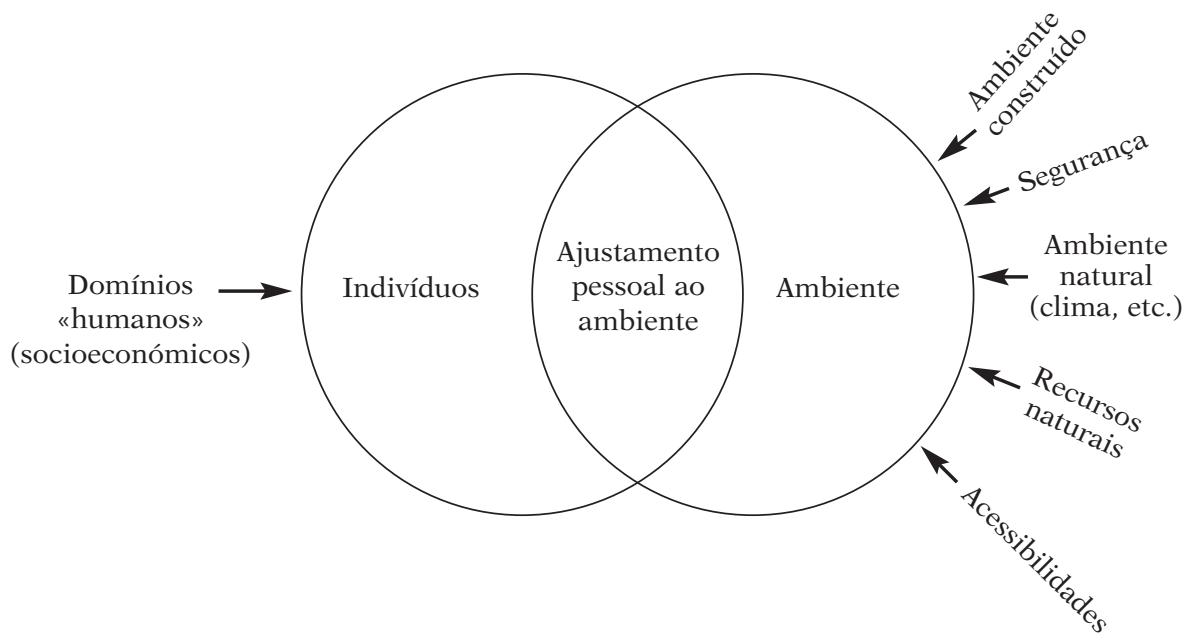

Fig. 5 - Domínios da qualidade de vida (baseado em KAMP et al., 2004)

Fig. 5 - Quality of life areas (based on KAMP et al., 2004)

(que podem afectar áreas urbanas) e a qualidade do ar; PAcione (1990) acrescenta o clima urbano como um risco em si mesmo, o que se pode considerar bastante discutível. Actualmente, salienta-se a importância das vagas de calor, sendo referida a possível acentuação dos seus efeitos nas áreas urbanas; a maior vulnerabilidade em relação a este fenómeno verificar-se-á em áreas urbanas com populações envelhecidas e de baixo nível socioeconómico (KALKSTEIN, 1997); contudo, ainda não foram apresentados resultados que demonstrem, de forma concludente, a maior perigosidade das vagas de calor nas áreas urbanas relativamente ao meio rural. A importância dada actualmente aos riscos térmicos prende-se igualmente com a crescente importância atribuída à variabilidade climática; a abordagem dos riscos no meio urbano tem assim de ser colocada no contexto da dupla variabilidade: do clima (implicando uma variação temporal da frequência dos fenómenos extremos) e das próprias cidades, cujas rápidas modificações implicam alterações na vulnerabilidade (MiTCHELL, 1998).

O conceito de sustentabilidade urbana tem-se tornado quase hegemónico na análise dos problemas relacionados com o ambiente urbano; segundo MiLls (2003) a nova utopia urbana é a cidade sustentável. As diferentes definições de sustentabilidade (Breheny, 1992; Barton, 1996; Newman, 1999; Partidário, 2001; Kamp et al., 2003) apontam para as duas perspectivas referidas anteriormente: melhoria da qualidade de vida; redução dos impactes sobre o ambiente. Contudo, ressalta, da leitura da bibliografia, que a principal preocupação dos autores que abordam o problema diz respeito aos impactes externos à cidades. O peso adquirido por este conceito é discutido por PINHo (1995), que considera o 'crescimento sustentável' uma ideia 'politicamente apelativa' mas vaga e ambígua, de duvidosa operacionalidade prática e que tem sido utilizada para justificar as mais variadas e contraditórias políticas. BARTON (1996) considera que a 'sobreexposição’ e uso inadequado do conceito podem levar facilmente a uma atitude cínica e depreciativa, inadequada segundo o autor, dado que atingir o desenvolvimento sustentável é o objectivo mais fundamental do Planeamento. 
No modelo de Newman (1999, fig. 1), a sustentabilidade urbana depende da redução dos inputs de energia e massa e dos outputs de resíduos (incluindo o calor). Tal como em diferentes publicações da Comunidade Europeia (CCE, 1990 e 2004; GPAU, 1996), o clima é analisado, no contexto da sustentabilidade urbana, essencialmente em termos da contribuição urbana para a variabilidade climática global; os aspectos climáticos especificamente urbanos são quase ignorados. YANNAS (2001) discute, de uma forma mais completa, o clima urbano na sua relação com a sustentabilidade. Salienta a necessidade de analisar aspectos como a contribuição da Ilha de Calor Urbano, quer para o aquecimento global, quer para a qualidade de vida.

A climatologia urbana deve, portanto, contribuir para as duas vertentes da sustentabilidade urbana: qualidade de vida e redução dos impactes ambientais externos. A articulação entre as intervenções orientadas para as duas vertentes, mais uma vez, tem-se revelado complexa.

\section{2. Áreas de aplicação da climatologia urbana}

O clima urbano pode afectar directamente a saúde e bem-estar humanos, sendo possível distinguir, nessa influência, diferentes factores, resumidos na figura 6. Quaisquer destes aspectos podem ser encarados simultaneamente como factor de conforto e de risco. MonTEIRo (2003) refere o conforto térmico, a qualidade do ar e os 'meteoros de impacto’ (agrupando uma grande diversidade de fenómenos, desde a precipitação aos tornados e tempestades eléctricas), capazes de afectar a vida urbana, como as principais áreas da aplicação da climatologia urbana.

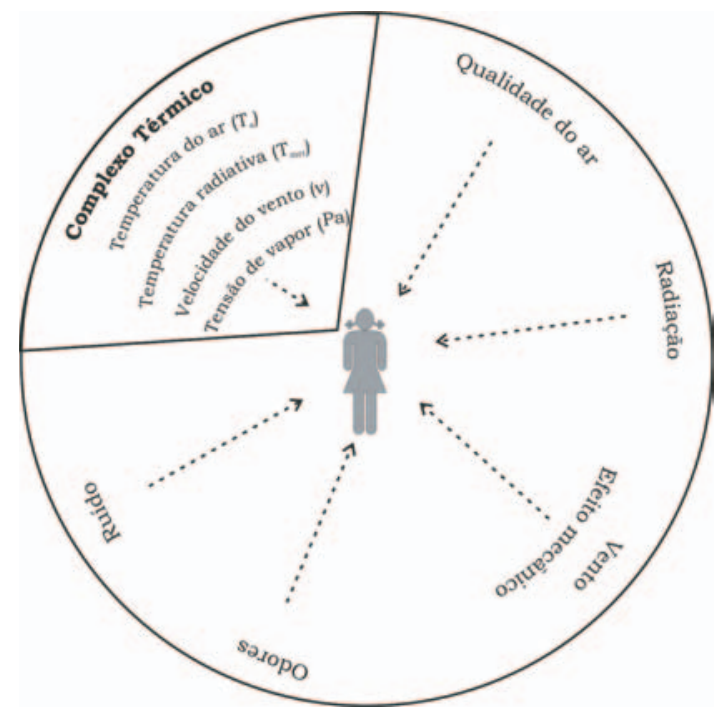

Fig. 6 - Principais factores atmosféricos com efeito bioclimático (adaptado de Jendritzky, 1993; Matzarakis, Beckröge e MaYer, 1998;

VDI, 1998; MATZARAKIS e MAYER, 2000)

Fig. 6-Main atmospheric factors with bioclimatic effects (adapted from JENDRITZKY, 1993; MATZARAKIS, BECKROGE and MAYER, 1998;

VDI 1998; MATZARAKIS and MAYER, 2000) 


\subsection{A qualidade do ar}

A qualidade do ar é, de longe, o aspecto mais focado, juntamente com o ruído, nomeadamente nas publicações comunitárias sobre o ambiente urbano (CCE, 1990 e 2004; GPAU, 1996).

O carácter particularmente nocivo da poluição atmosférica, relativamente aos outros factores de risco no ambiente urbano, justifica a importância que lhe é dada. Contudo, a melhoria da qualidade do ar nas cidades dos países desenvolvidos, nas últimas décadas, leva a que a atenção se oriente agora para os aspectos térmicos do clima urbano (JENDRITZKY et al., 2000). Por outro lado, a influência global do ambiente urbano sobre os indivíduos é exercida, conjuntamente, pelos diferentes factores referidos na figura 6 (Fukuoka, 1997; Matzarakis, Beckröege e MaYer, 1998; MatZarakis, 2001).

\subsection{O conforto e a saúde}

Os elementos atmosféricos com uma influência térmica directa sobre os seres humanos são a temperatura do ar, a temperatura radiativa, a humidade atmosférica e o vento, designados, em conjunto, por complexo térmico (fig. 6).

A influência directa do complexo térmico sobre o conforto e a saúde dos seres humanos corresponde a uma primeira ordem de impactes (AuliciEMs, 1997 - fig. 7), recebendo essencialmente respostas individuais, involuntárias e determinadas pelas condições térmicas. Numa escala temporal mais longa (impactes de ordem mais avançada) as respostas são fundamentalmente colectivas, com uma forte condicionante cultural (que modela a forma como o ambiente atmosférico é percebido e valorizado) e um carácter socioeconómico e tecnológico. A este nível, a adaptação às condições térmicas pode levar ao aumento do consumo de energia (através das interacções entre o clima de exterior e de interior - SHEAFFER e REITER, 1988; MEIER, 1990/91; TAESLER, 1990/91; RosEnFeld et al., 1995 e 1998; SANTAMOURIS, 2001b; AKBARY e DAVIS, 1992; AKBARY et al. 1997), ao incremento da emissão de resíduos e, a longo prazo, pode afectar as próprias variações de temperatura.

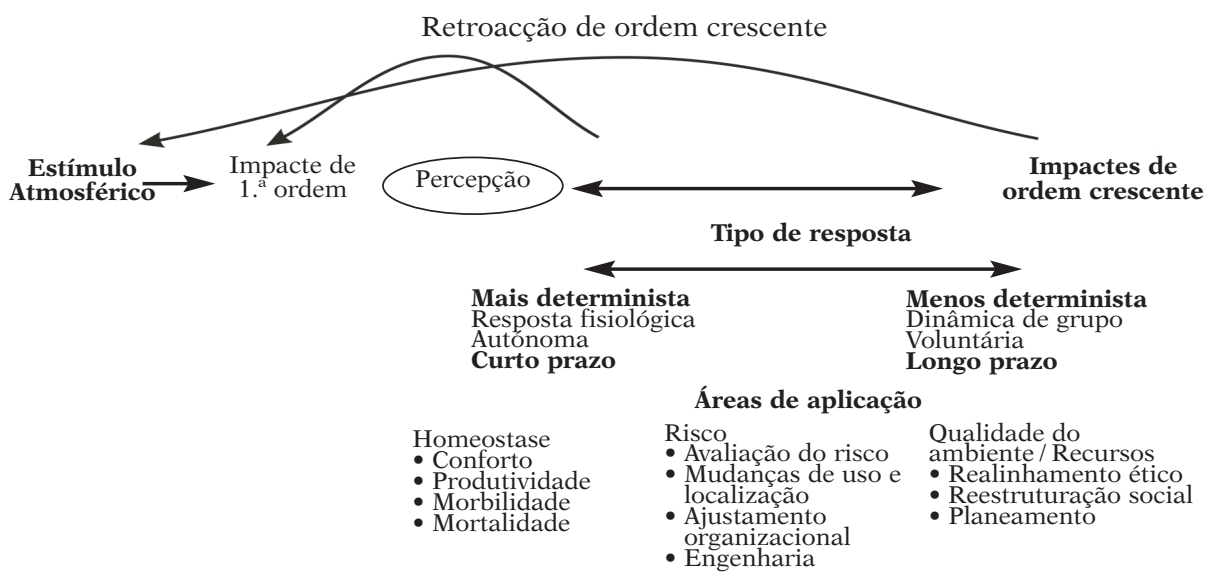

Fig. 7 - Continuum de resposta humana aos estímulos atmosféricos (baseado em Auliciems, 1997)

Fig. 7 - Continuum of human response to atmospheric stimuli

(based on AULICIEMS, 1997) 
O conforto climático (térmico e mecânico) surge assim como um objectivo chave na intervenção no espaço urbano. Foram desenvolvidos diversos modelos para avaliação da influência térmica integrada das condições atmosféricas sobre os seres humanos. Os mais usuais foram criados para a avaliação das condições térmicas de interior, em situações estereotipadas e estacionárias (steady-state conditions - PARSONS, 1993; VDI, 1998). Este tipo de abordagem foi dominada pelo paradigma do óptimo térmico universal, determinado por um pequeno número de parâmetros ambientais. Actualmente, muitos autores consideram estes modelos 'redutores', por associarem exclusivamente o conforto térmico a parâmetros físicos e fisiológicos e por restringirem o estudo a grupos escolhidos em ambientes artificiais, tornando difícil a generalização a situações e populações reais. As diferenças de percepção térmica entre indivíduos ou entre populações foram secundarizadas (DE DEAR e LEAW, 1990; De DEAR et al., 1991; Auliciems e DE DEAR, 1997). É uma perspectiva que tem a sua expressão mais completa em FANGER (1972), servindo de base a índices de conforto largamente utilizados, como o Predicted Mean Vote (PMV - FAnger, 1972; Gonzalez et al. 1974; PARsons, 1993; VDI, 1998). Apesar das críticas apontadas, foram feitas numerosas aplicações de modelos deste tipo ao estudo das condições térmicas de exterior (por exemplo em DE DEAR, 1989; JENDRITZKY e Gratz, 1998; MatZARAKYs e MAYER, 1998 e 2000; KuwABARA et al., 2002; ANDrAdE, 2003a e b; CHEN et al. , 2004), sobretudo se o principal objectivo for a análise da variação geral das condições bioclimáticas, sem referência a grupos ou indivíduos particulares. O facto de estes modelos serem, principalmente, do tipo estacionário, é aceitável quando a análise incide essencialmente sobre a variação espacial das condições bioclimáticas.

Diversos estudos feitos, quer em edifícios, quer no exterior, demonstram uma relação relativamente fraca entre os resultados dos índices de conforto tradicionais e o 'voto térmico' directo (Auliciems e DE DEAR, 1997). CADIMA (2000, citando vários autores) refere que a preferência térmica observada corresponde, quase sempre, a temperaturas superiores às previstas através do PMV. Segundo DE DEAR e Brager (2001), os modelos tradicionais de conforto térmico encaram os indivíduos como receptores passivos dos estímulos térmicos. A grande variabilidade de respostas e preferências térmicas levaram a substituir o paradigma do 'óptimo térmico universal' por uma abordagem 'adaptativa' (adaptive models - Auliciems e DE DEAR, 1997; CADIMA, 2000; De DEAR e Brager, 2001) que valoriza a importância da aclimatação às condições climáticas prevalecentes, variáveis no espaço e no tempo, a diversidade de respostas entre grupos (diferenças com origem étnica, social, de género, etc.), o papel da 'adaptação térmica' comportamental, da expectativa térmica e das motivações (Auliciems e DE DEAR, 1997; Cadima, 2000; De Dear e Brager, 2001; Nikolopoulou et al., 2001; Nikolopoulou e Stemmers, 2003). A abordagem adaptativa insere-se na tendência actual (em Climatologia, como noutros domínios) de valorização da variabilidade e da 'diferença'.

Segundo CADima (2000), a abordagem adaptativa é particularmente relevante no estudo do conforto térmico no exterior, em que se verifica uma multiplicidade de adaptações individuais ao ambiente térmico (muito mais variável, no espaço e no tempo, do que o ambiente de interior). Note-se, porém, que os estudos com modelos adaptativos foram feitos, sobretudo, em condições de interior de edifícios. Alguns trabalhos começam, contudo, a surgir, em que são realizados 'estudos de campo' sobre o conforto térmico no exterior, normalmente baseados em entrevistas a frequentadores dos locais ou em respostas de voluntários (Nikolopoulou et al., 2001; NiKolopoulou e STEMmers, 2003; Ahmed, 2003; Givoni et al., 2003). Pode-se considerar que não foram ainda definidas as metodologias mais adequadas a este tipo de estudo. 


\section{Dificuldades de aplicação}

A escassa aplicação da Climatologia ao Planeamento urbano deve-se às dificuldades de comunicação entre investigadores e agentes do planeamento, à formação desadequada dos planeadores e arquitectos e à falta de compreensão dos climatólogos quanto às reais necessidades do planeamento urbano e o tipo de prioridades definidas (OKe, 1984b; Alcoforado, 1999; Mills, 1999; Ojo e AdedoKum, 1999; Eliasson, 2000; Eliasson e SVENSSON, 2002). A preocupação com as condições climáticas verifica-se quase exclusivamente no desenho de edifícios isolados, considerando sobretudo o ambiente interior e, mais raramente, o espaço exterior contíguo (Golany, 1996; AlcofoRADO, 1999); a aplicação real ao planeamento urbano é muito limitada, ressalvando alguns casos pontuais, nem sempre felizes (LANDSBERG, 1981). A simples existência de legislação que obrigue à utilização de informação climática não é suficiente se não existir vontade política de a utilizar (Тнамм et al., 1999). Num estudo sistemático sobre a utilização da informação climática no planeamento urbano, na Suécia, EliASSON (2000) identificou como principais obstáculos (não hierarquizados) à aplicação da Climatologia no Planeamento urbano os problemas de comunicação entre os climatólogos e diferentes agentes de planeamento, os conflitos de interesses, as limitações económicas, a falta de conhecimentos, a baixa prioridade atribuída aos aspectos climáticos, a falta de clareza e coerência das políticas e o curto prazo de prazo de implementação dos projectos.

Segundo MilLs (1999), a climatologia urbana actual evoluiu no sentido do aprofundamento da sua fundamentação física, recorrendo a modelos muito complexos, mas aplicados a cenários urbanos simplificados (usualmente urban canyons estereotipados). De acordo com o autor, esta evolução da climatologia urbana torna os seus resultados de utilidade reduzida para a Arquitectura e Desenho Urbano, que continuou a fazer uma abordagem climática mais empírica, baseado em 'estudos de caso', com objectivos restritos e práticos.

Mills (1999) e Eliasson e Svensson (2002) consideram que a importância dada, tradicionalmente, ao estudo do campo térmico nocturno com tipos de tempo estáveis limita a aplicabilidade, pela excepcionalidade destes tipos de tempo em alguns climas regionais e por ser um fenómeno nocturno, próprio do período em que os indivíduos estão menos activos e em que o controlo das condições ambientais (de interior) é mais fácil. JENDRITZKY et al. (2000), pelo contrário, consideram que a ilha de calor urbano é 'sem dúvida' relevante para a saúde humana, pelo que o planeamento urbano deve ter, como um dos seus principais objectivos, a sua mitigação. Uma melhor definição do conceito de ilha de calor urbano poderá ser necessária para esclarecer esta questão.

Uma maior aplicabilidade da investigação, em climatologia urbana, passa por dar uma maior atenção aos parâmetros atmosféricos que condicionam significativamente o ambiente urbano, ao estudo de padrões térmicos no período diurno e sob tipos de tempo diversificados, ao estudo das relações entre as condições de exterior e de interior e ao comportamento térmico de estruturas urbanas diferentes do urban canyon padrão.

\section{Aplicação da climatologia urbana no Planeamento a diferentes escalas}

A aplicação da Climatologia ao Planeamento urbano pode ser feita em diferentes contextos (BITAN, 1988; THAmm et al., 1999), nomeadamente:

- Construção de novos edifícios de grandes dimensões;

- Modificações em estruturas urbanas já existentes;

- Novas implantações urbanas. 
A informação climática pode ser utilizada em diferentes níveis do Planeamento. BITAN (1988), distinguiu três níveis essenciais:

- No planeamento regional, a informação climática, sobretudo de mesoescala (MATZARAKIS, 2001), é utilizada na selecção de novas localizações, no planeamento do uso do solo à escala regional e na minimização dos riscos ambientais.

- O nível privilegiado de aplicação da Climatologia ao Planeamento urbano é o do Settlement Planning, correspondente aproximadamente à escala local. Pode integrar-se neste nível a cartografia topoclimática, largamente desenvolvida na Alemanha e na Suíça e que constituem exemplos felizes de divulgação da informação climática, de uma forma sintética e aplicável (KuTTLER, 1988; Alcoforado, 1999; SchERER et al., 1999; FrIEDRICH et al., 2001). A informação climática pode ser utilizada, por exemplo, na selecção da forma urbana geral e do uso do solo, mas também em aspectos de maior pormenor, como o dimensionamento e características dos espaços abertos, utilização da vegetação e cores predominantes, podendo ir até ao planeamento de conjuntos residenciais ao nível do quarteirão (BITAN, 1988; GolanY, 1996; RAHAMIMOFF, 1984). KuTLler (1988) considera que a climatologia urbana aplicada deve debruçar-se, sobretudo, sobre o dimensionamento e desenho das áreas verdes (com o objectivo de reduzir o aquecimento urbano), com a manutenção de corredores de circulação de ar fresco e limpo e com as medidas destinadas a reduzir a emissão de poluentes.

- O nível do planeamento dos edifícios individuais e do seu espaço contíguo é aquele em que a informação climática (aqui de carácter microclimático) tem assumido maior relevância (Olgyay, 1963; BRAZEl e Martin, 1997; GivONI, 1978 e 1998; Mills, 1999), atingindo a sua maior expressão na moderna arquitectura bioclimática (SzoKOLAY, 1997).

É no nível intermédio (Settlement Planning) que se discutem as características gerais da implantação urbana; é também a este nível que os factores locais e de mesoescala têm maiores implicações (nomeadamente em relação ao desenvolvimento da ilha de calor urbano). A actual discussão da forma urbana mais adequada para garantir o desenvolvimento sustentável enquadra-se nesta temática mas, pela importância que adquiriu, merece uma breve abordagem em separado.

\section{Clima, forma e densidade urbanas}

Um dos aspectos actualmente discutidos é o do ajustamento da forma urbana para aumentar a sustentabilidade. Desde o início da década de 90 do séc. XX, têm sido desenvolvidos argumentos que defendem o incremento da densidade de ocupação e intensificação da utilização dos espaços urbanos, como forma de incrementar a sustentabilidade, reduzindo o consumo de espaço e de energia e as emissões de poluentes pelos transportes (BARTON et al., 1995; BREHENY, 1996; GPAU, 1996; Whitford et al., 2001; SteEMER, 2003a e b; CCE, 2004). Surge assim um novo paradigma (a 'cidade compacta'), em evidente contradição com os modelos de 'utopia climática' urbana, dominante nas décadas de 60 e 70 do séc. XX (LANDSBERG, 1973) preconizavam espaços urbanos de baixa densidade.

Este objectivo contrasta também, de forma muito evidente, com a realidade do crescimento urbano actual, baseada em diferentes tipos de desconcentração (BREHENY, 1996; Thomas e Cousins, 1996; CCE, 2004). Aparentemente, a cidade compacta não surge aos olhos da maioria dos cidadãos como o espaço em que estes gostariam de viver (JENKS et al., 1996); para contrariar esta tendência, é necessário provar, na prática, que as soluções de elevada densidade podem proporcionar uma elevada qualidade de vida (BREHENY, 1996; CCE, 2004). 
Os principais argumentos a favor da densificação urbana são:

a) Redução do consumo de energia pelos transportes;

b) Menor emissão de poluentes pelos transportes;

c) Diminuição das perdas de calor pelos edifícios, reduzindo portanto as exigências de energia para aquecimento;

d) Menor consumo de espaço pela urbanização.

Estas vantagens são ampliadas pelas utilizações mistas na ocupação do solo (Barton et al., 1995; GPAU, 1996; SteEmers, 2003b; CCE, 2004).

Contudo, de acordo com Burton et al. (1996), Thomas e Cousins (1996) e Welbank (1996), não existem nem modelos teóricos, nem evidências empíricas que permitam sustentar, com segurança, o paradigma da 'cidade compacta', nem tão pouco existem os instrumentos que tornem possível a sua concretização. Argumentos aparentemente 'óbvios', como o da redução do consumo de energia pelos transportes, têm sido rebatidos por diferentes autores, sendo apenas possível provar, neste aspecto, ganhos marginais (BREheney, 1996; Thomas e Cousins, 1996)

Esta questão tem sido discutida em termos de dicotomia concentração/dispersão urbana, tendo em geral as soluções de compromisso poucos defensores (BREHENY, 1996); contudo, de acordo com este autor, numa perspectiva realista, soluções de compromisso podem permitir aliar as vantagens de diferentes formas de dispersão e de concentração. GOLANY (1996) considera que uma solução intermédia (clustered form) pode apresentar vantagens em alguns tipos de clima. BARTON et al. (1995) recomendam uma estrutura urbana que combine densidades elevadas nas áreas residenciais (sendo recomendados aproximadamente 100 habitantes/hectare) com áreas abertas extensas, permitindo manter densidades gerais relativamente baixas.

Não são praticamente consideradas, nos diferentes trabalhos em que se discute este problema, as consequências climáticas de um incremento da densidade urbana; de acordo com o estado actual dos conhecimentos nesta área, são bastante previsíveis alguns efeitos do incremento da densidade dos edifícios:

- redução da velocidade média do vento e, consequentemente, degradação das condições de ventilação;

- aumento da intensidade da ilha de calor urbano, devido à modificação do balanço de radiação de grande comprimento de onda, redução da ventilação, incremento da concentração da produção de calor de origem antrópica e diminuição da cobertura vegetal.

STEEMERS (2003a) salienta que a pesquisa que permite suportar (ou refutar) as vantagens da densificação é reduzida; segundo o autor, o desenho urbano, na escala microclimática, tem maior importância sobre o consumo energético do que a densidade propriamente dita, dado que o consumo de energia pelos edifícios é, na União Europeia, pelo menos o dobro da dos transportes.

A diminuição da perda de calor pelos edifícios é o principal argumento apontado pelo Grupo de Peritos sobre Ambiente Urbano (GPAU, 1996) o qual sugere, explicitamente, como uma das opções políticas referentes à promoção da eficiência energética dos sistemas urbanos, a densificação da construção como forma de reduzir o consumo de energia para aquecimento e ventilação (GPAU, 1996). O Grupo de Peritos assume que essa política urbana pode ter efeitos 'microclimáticos' negativos sobre o conforto dos cidadãos, mas, de acordo com os autores, esses efeitos são 'mais que compensados' pela 
redução do consumo de energia para aquecimento. Fica claro que este Grupo defende como positivo o incremento da 'ilha de calor urbano', mas não de que forma é que isso pode reduzir as necessidades de ventilação; por outro lado, estas considerações não têm em conta os diferentes contextos climáticos europeus, o que é, no mínimo, estranho (sem dúvida que as necessidades relativas de aquecimento e arrefecimento serão diferentes, por exemplo, em Sevilha e em Estocolmo).

Segundo STEMMERS (2003b), os edifícios isolados têm perdas energéticas superiores às dos apartamentos em $40 \%$. Contudo, este autor salienta que o principal factor de redução do consumo de energia é a incidência de radiação solar nos edifícios, sendo indispensável conciliar a densidade urbana com condições de insolação adequadas. Em qualquer caso, para STEMMERS (2003b), é possível atingir densidades relativamente elevadas antes que o impacto negativo no consumo de energia se faça sentir; note-se, por outro lado, que as conclusões deste autor dizem respeito ao clima de Inglaterra; em climas onde as necessidades de aquecimento sejam menores, a importância da densidade urbana pode ser claramente reduzida.

A outra vantagem da densificação urbana habitualmente apontada é a redução da utilização dos transportes individuais, com as consequências já referidas, embora STEMMERS (2003b) saliente que esse efeito só se verifica se o crescimento urbano for acompanhado por um adequado desenvolvimento do sistema de transportes. MiLls (2003) faz notar que uma elevada densidade urbana pode levar a à diminuição das emissões totais de poluentes pelos veículos, mas também a uma forte redução das condições de dispersão dos poluentes ao nível das ruas e, portanto, a um aumento da exposição dos indivíduos à poluição atmosférica.

BARTON et al. (1995) e WHITFORD et al. (2001) salientam que elevadas densidades podem prejudicar a qualidade do ambiente, sobretudo devido à redução da cobertura vegetal. Por outro lado, as áreas de elevada densidade urbana são socialmente repulsivas se não forem capazes de fornecer uma boa qualidade de vida (CCE, 2004) e, neste caso, a extensão dos espaços urbanos sob a forma de «subúrbios» de baixa densidade é inevitável; segundo CCE (2004), os limiares de densidade que permitem uma razoável qualidade de vida já foram ultrapassados em muitas áreas urbanas, apesar de esta entidade defender o princípio geral de 'urbanização de alta densidade com usos mistos' como via para a sustentabilidade. Segundo WHITFORD et al. (2001), os problemas colocados pela densificação urbana podem ser atenuados por um bom desenho urbano e por diferentes soluções técnicas. A participação dos climatólogos urbanos nesta discussão afigura-se, portanto, indispensável.

\section{BIBLIOGRAFIA}

Ahmed, K. S. (2003) - Comfort in urban spaces: defining the boundaries of outdoor thermal comfort for the tropical urban environments. Energy and Buildings, 35(1): 103-110.

AKBARI, H.; Davis, S. et al. (1992) - Cooling our communities. A guidebook on tree planting and lightcolored surfacing. U.S. Environmental Protection Agency, Office of Policy Analysis, Climate Change Division. Lawrence Berkeley National Laboratory Report No. LBL-31587: 217.

AKBARI, H.; KURN, D. M. et al. (1997) - Peak power and cooling energy savings of shade trees. Energy and Buildings, 25(2): 117-126.

Alcoforado, M. J. (1985) - Dois exemplos de utilização de termografias obtidas de avião. Comunicação ao Primeiro Seminário sobre Cartografia Temática e Cadastral, LNEC, Lisboa: 23 p. pol. 
Alcoforado, M. J. (1986) - Contribution to the study of Lisbon's heat island. Analysis from an infra-red image. Freiburger Geographische Hefte, 26: 165-176.

Alcoforado, M. J. (1987) - Brisas estivais do Tejo e do Oceano na região de Lisboa. FinisterraRevista Portuguesa de Geografia, XXII (43): 71-112.

Alcoforado, M. J. (1991) - Influence de l'advection sur les champs thermiques urbains à Lisbonne. Publications de l'Association Internationale de Climatologie, 4: 29-35.

Alcoforado, M. J. (1992) - O clima da região de Lisboa, contrastes e ritmos térmicos. Memórias do Centro de Estudos Geográficos, Faculdade de Letras da Universidade de Lisboa, Lisboa.

Alcoforado, M. J. (1995) - L'extrapolation spatiale des données thermiques en milieu urbain. Publications de l'Association Internationale de Climatologie, 7: 493-502.

Alcoforado, M. J. (1996) - Comparaison des ambiances bioclimatiques estivales d'espaces verts de Lisbonne. Publications de l'Association Internationale de Climatologie, 9: 273-280.

Alcoforado, M. J. (1999) - Aplicação da Climatologia ao Planeamento urbano. Alguns apontamentos. Finisterra - Revista Portuguesa de Geografia, XXXIV (67-68): 83-94.

Alcoforado, M. J.; ANdrade, H. (2005) - Nocturnal urban heat island in Lisbon (Portugal): main features and modelling attempts. Theoretical and Applied Climatology, versão electrónica.

Alcoforado, M. J.; Lopes, A.; Andrade, H. (1998) - Studies on urban climatology in the area of Lisbon. Pre-Regional Conference Meeting on the Commission on Climatology, Évora: 45-46.

Alcoforado, M. J.; Lopes, A.; Andrade, H. (1999) - Cartes thermiques et cartes du "risque" d'occurrence de basses températures en milieu urbain à Lisbonne. Publications de l'Association Internationale de Climatologie, 12: 433-441.

Alcoforado, M. J.; Taborda, J. P. (1996-1997) - O clima de Évora. Contrastes térmicos locais.

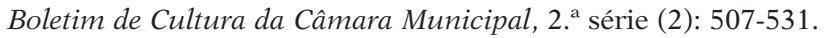

Americam Meteorological Society (AMS) (2000) - Glossary of Meteorology. Americam Meteorological Society, versão electrónica.

Andrade, H. (1994) - Poluição Atmosférica e Clima de Lisboa. Aspectos da Variação Espacial e Temporal no Semestre de Inverno. Dissertação de Mestrado, Faculdade de Letras da Universidade de Lisboa, Lisboa.

ANDRADE, H. (1998a) - O desconforto térmico estival em Lisboa. Uma abordagem bioclimática. Finisterra - Revista Portuguesa de Geografia, XXXIII (66): 41-58.

ANDRADE, H. (1998b) - A model of spatial interpolation of nocturnal winter temperatures in Lisbon. Pre-Regional Conference Meeting on the Commission on Climatology, Évora: 23-24.

ANDRADE, H. (2000) - The thermal confort in a green space of Lisbon: the garden of the Gulbenkian Foundation. 4th Conference on Contemporary Topoclimatic Research, Warszawa, book of abstracts: 01-02.

Andrade, H. (2003) - Bioclima humano e Temperatura do ar em Lisboa. Dissertação de Doutoramento em Geografia Física, Faculdade de Letras da Universidade de Lisboa: 435.

ANDRADE, H.; LOPES, A. (1998) - A utilização de um SIG para estimação das temperaturas em Lisboa. In F. F. Garcia, E. G. Gallego and R. C. Torrecilla (ed.) - Clima y ambiente urbano en ciudades Ibéricas e IberoAmericanas. Ed. Parteluz. Madrid: 85-91.

ARNFIELD, A. J. (2003) - Two decades of urban climate research: a review of turbulence, exchanges of energy and water, and the urban heat island. International Journal of Climatology (23):1-26.

Auliciems, A. (1997) - Comfort, clothing and health In R. Thompson and A. Perry (ed.) - Applied climatology. Principles and practice. Routledge, Londres: 155-174. 
Auliciems, A.; De Dear, R. (1997) - Thermal adaptation and Variable Indoor Climate Control. In A. Auliciems (ed.) - Advances in Bioclimatology - 5. Human Bioclimatology. Springer, Queensland (Australia): 61-86.

BARTON, H. (1996) - Planning for sustainable development. In C. GREED (ed.) - Investigating town planning, changing perspectives and agendas. Longman, Edimburg: 115-104.

Barton, H.; Davls, G.; Guise,R. (1995) - Sustainable Settlements: a Guide for Planners. Designers and Developers. Faculty of the Built Environment, University of the West of England.

BITAN, A. (1988) - The methodology of applied climatology in planning and building. Energy and Building, 11: 1-10.

Brazel, A.; Martin, J. (1997) - Town planning, architecture and building. In R. Thompson and A. Perry, (eds) - Applied Climatology, Principles and Pratice. Routledge, London, part 3: 175-186.

BRehenY, M. J. (1992) - Towards sustainable urban development. In A. M. MANNION and S. R. BowLBY (eds) - Environmental Issues in the 1990s. John Wiley \& Sons, Chichester: 277-290.

Breheny, M. J. (1996) - Centrists, Decentrists and Compromisers: View on the future of urban form. In M. Jenks; E. Burton and K. Wiliams (eds) - The Compact City, a sustainable urban form? E \& F N Spon, London: 13-35.

Burton, E; Williams, K.; JenKs, M. (1996) - The compact city and urban sustainability. In M. JenKs; E. Burton and K. Wiliams (eds) - The Compact City, a sustainable urban form? E \& F N Spon, London: 231-247.

Cadima, P. S. P. (2000)-Transitional Spaces, Architectural. Architectural Association Graduate School, London.

Chen, H., Ooka, R., Harayama, K., Kato, S.; Li, X. (2004) - Study on outdoor thermal environment of apartment block in Shenzhen, China, with coupled simulation of convection, radiation and conduction. Energy and Buildings, 36: 1247-1258.

Choisnell, E. (1984) - Notions d'échelle en climatologie. La Météorologie, série VII, n. ${ }^{\circ}$ 4: 44-52.

Comissão dAs Comunidades EuRopeIas (CCE) (1990) - Livro verde sobre o ambiente urbano. Comunicação da Comissão ao Conselho e ao Parlamento. Serviço das Publicações Oficiais das Comunidades Europeias, Bruxelas.

Comissão das Comunidades EuRopeias (CCE) (1995) - A política de coesão e o Ambiente. Comunicação da Comissão ao Conselho, ao Parlamento Europeu, ao Comité Económico e Social e ao Comité das Regiões, COM (95) 509 final, Bruxelas.

Comissão das Comunidades EuRopeias (CCE) (2004) - Para uma estratégia temática sobre ambiente urbano. 11.02.2004, COM (2004) 60 final, Bruxelas.

DE DEAR, R. J. (1989) - Diurnal and seasonal variations in the human thermal climate of Singapore. Singapore Journal of Tropical Geography, 10(1): 13-26.

De Dear, R.; Brager, G. S. (2001) - The adaptive model of thermal comfort and energy conservation in the built environment. International Journal of Biometeorology, 45: 100-108.

DE DEAR, R. J.; LEAW, K. G. (1990) - Indoor climate and thermal comfort in high-rise public housing in an equatorial climate: a field study in Singapore. Atmospheric Environment, 24B (2): 313-320.

De Dear, R. J.; LeaW, K. G.; Foo, S. C. (1991) - Thermal comfort in the humid tropics: field experiments in air conditioned and naturally ventilated buildings in Singapore. International Journal of Biometeorology, 34: 259-265. 
Deus, R. J. R. C. (2004) - Diagnóstico de extremos meterológicos para detecção de ilha de calor em regiões urbanas: aplicação à cidade de Lisboa. Área de Meteorologia. Universidade de Évora, Évora: 283.

Douglas, I. (1983) - The urban environment. Edward Arnold, London.

Douglas, I. (1987) - The influence of human geography on physical geography. Progress in Human Geography, 11 (4): 517-540.

Eliasson, I. (2000) - The use of climate knowledge in urban planning. Landscape and Urban Planning, 48: 31-44.

Eliasson, I.; Svensson, M. K. (2002) - Spatial temperature variations and urban land use - a statistical approach. In M. K. Svensson (ed.), Urban climate in relation to land use, planning and comfort. Goteborg University, Department of Earth Sciences, Goteborg.

Epstein, P. R.; Rogers, C. (2004) - Inside the greenhouse, the impacts of CO2 and climate change on public health in the inner city. Report from the center for health and the global environment Harvard Medical School.

FANGER, P. O. (1972) - Thermal comfort. McGraw-Hill, Nova York.

FrIEDRICH M; GRÄTZ, A.; JENDRITZKY, G. (2001) - Further development of the urban bioclimate model UBIKLIM, taking local wind systems into account. Meteorologische Zeitschrift, 10(4): 267-272.

FuKuoka, Y. (1997) - Biometeorological studies on urban climate. International Journal of Biometeorology, 40: 54-57.

Ganho, N. (1996) - Espaços verdes no interior do tecido urbano de Coimbra, Portugal: Contrastes topoclimáticos, influência bioclimática e riscos de poluição atmosférica. Territorium, 3: 35-55.

Ganho, N. (1998) - O clima urbano de Coimbra: estudo de climatologia local aplicada ao ordenamento urbano. Dissertação de Doutoramento. Faculdade de Letras da Universidade de Coimbra Instituto de Estudos Geográficos, Coimbra.

Givoni, B. (1978) - L'homme, l'architecture et le climat. Ed. du Moniteur, Paris.

GivonI, B. (1998) - Climate considerations in building and urban design. John Wiley \& Sons, Inc., New York: 464.

Givoni, B., Noguchi, M.; SaAroni, H.; Pochter, O; Yaacov, Y.; Feller, N.; Becker, S. (2003) Outdoor comfort research issues. Energy and Buildings, 35: 77-86.

GóIs, J. E. S. (2002) - Contribuição dos modelos estocásticos para o estudo da climatologia urbana. Faculdade de Engenharia da Universidade do Porto - Departamento de Engenharia de Minas, Porto.

Golany, G. S. (1996) - Urban design morphoplogy and thermal perfomance. Atmospheric Environment, 30(3): 455-465.

Goldreich, Y. (1984) - Urban topoclimatology. Progress in Physical Geography, 8 (3): 336-364.

Gonçalves, H., Panão, M. O.; Camelo, S. M. L.; Ramalho, A.; Graça, J. M.; Aguiar, R. (2004) Ambiente Construído, Clima Urbano, Utilização Racional de Energia. INETI, Lisboa: 58.

Gonzalez, R. R.; Nishi, Y.; Gagge, A. P. (1974) - Experimental evaluation of Standard Effective Temperature, a new biometeorological Index of Man's thermal discomfort. International Journal of Biometeorology 18 (1): 01-15.

GrÄtZ; A.; JendRITZKY, G. (1995) - Preliminary climatic study of the Karlsruhe area: Part 1 - Ubiklim, a tool for climatological - related planning in urban environment. In K. M. MORIYAMA and H. Zimmermenn (eds) - Proceedings of a Japanese-German Meeting, Hoschelle, Climate analysis for urban planning, 22-23: 143-148. 
Grimmond, C. S.; OKE, T. (1995) - Comparison of heat fluxes from summertime observations in the suburbs of four north-american cities. Journal of Applied Climatology, 34: 873-889.

Grupo de Peritos sobre o Ambiente Urbano (GPAU) (1996)-Cidades Urbanas Sustantáveis. Comissão Europeia, Bruxelas.

JendRitzKy, G. (1993) - Human biometeorology, Part I. Experientia, 49 (9): 733-740.

JENDRITZKY G.; GRÄTZ, A. (1998) - Mapping human bioclimates in various scales with particular reference to urban environment. Vol. Second. Urban Environment Symposium, American Meteological Society, Albuquerque-Novo México: 168-171.

Jendritzky, G.; Staiger, H.; Bucher, K.; GrätZ, A.; Laschewski, G. (2000) - The perceived temperature: the method of Deutsher Wetterdienst for the assessment of cold stress and heat load for the human body. Internet workshop on windchill, April 3-7, 2000, Meteor. Service of Canada, Environment Canada.

Jenks, M.; Burton, E.; Wiliams. K. (1996) - Compact Cities and Sustainability: an introduction. In M. Jenks; E. Burton and K. Wiliams (eds). - The Compact City, a sustainable urban form? E \& F N Spon, London: 3-8.

KALKSTEIN, L. S. (1997) - Climate and human mortality: relationships and mitigating measures. In A. Auliciems (ed.) - Advances in Bioclimatology-5. Human Bioclimatology. Springer, Queensland (Australia): 161-177.

Kamp, I. V.; Leidelmeijer, K.; Marsman, G.; Hollander, A. D. (2003) - Urban environmental quality and human well-being: Towards a conceptual framework and demarcation of concepts; a literature study. Landscape and Urban Planning, 65(1-2): 5-18.

Katzchner, L.; Reinhold, M.; Gonçalves, D. A.; Ferreira, T. A. (1999) - The use of urban climatological data for aspects of town planning in notheast Portugal. $15 .^{\circ}$ International Congress of Biometeorology \& International Conference on Urban Climatology. Macquarke University, Sydney - Australia, ed. CD.

Knox, P. (1987) - Urban Social Geography. Longman, Harlow.

KUTTLER, W. (1988) - Spatial and temporal structures of the urban climate - a survey. In K. GREFEN and J. LoBel - Environmental Meteorology. Kluwer Academic Publishers, Dordrecht, 305-344

Kuwabara, K.; Mochida, T. et al. (2002) - Evaluation of Thermal Sensation in Urban Environment. Proceedings of the 8th International Conference on air Distribution Rooms, Copenhagen: 417-420.

LANDSBerg, H. E. (1973) - The meteorologically utopian city. Bulletin of the American Meteorological Society, 58: 86-89.

Landsberg, H. E. (1981) - The urban climate. Academic Press, New York.

LaWrence, R. J. (2003) - Human ecology and its applications. Landscape and Urban Planning 65 (1-2): 31-40.

Lopes, A. (1994) - Padrões Térmicos do Clima Local na Região de Oeiras. Dissertação de Mestrado em Geografia Física e Regional. Faculdade de Letras da Universidade de Lisboa. Lisboa: 220.

Lopes, A. (1995) - Drenagem e acumulação de ar frio em noites de arrefecimento radiativo. Um exemplo no vale de Barcarena (Oeiras). Finisterra - Revista Portuguesa de Geografia XXX (5960): 149-164.

Lopes, A. (1996) - Drainage et accumulation de l'air froid pendant les nuits anticycloniques. Le cas de la vallée de Barcarena. Lisbonne - Portugal. 9ème Colloque International de Climatologie, Strasbourg.

LOPES, A. (1998) - Contrastes térmicos nocturnos e acumulação de ar frio em áreas urbanas do sul da Península de Lisboa. Finisterra - Revista Portuguesa de Geografia XXXIII (66): 25-40. 
LoPEs, A. (2003) - Modificações no clima urbano de Lisboa como consequência do crescimento urbano. Vento, ilha de calor de superfície e balanço energético. Dissertação de Doutoramento. Faculdade de Letras da Universidade de Lisboa, Lisboa: 375.

Lopes, A.; VIEIRA, H. (2001) - Heat fluxes from Landsat images: a contribution to Lisbon urban planning. In C. JÜRGENS (ed.) - Remote sensing in urban areas. Fernerkundung in urbanen Räumen. Regensburg Geographische Schriften, Regensburg, 35: 169-176.

LOWRY, W. P. (1977) - Empirical estimation of urban effects on climate: a problem analysis. Journal of Applied Meteorology, 16: 129-153.

MatZarakis, A. (2001) - Die thermische Komponente des Stadtklimas. Berichte des Meteorologischen Institutes der Universität Freiburg, Freiburg: 267.

Matzarakis, A.; Beckröge, W.; MAYer, H. (1998) - Future perspectives in applied urban climatology. In Proceedings of the second Japanese-German meeting, Report of Research Center for Urban Safety and Security, Kobe University, Special Report n. ${ }^{\circ}$ 1: 109-122.

Matzarakis, A.; MaYer, H. (1998)-Investigations of Urban Climates Thermal Component in Freiburg, Germany. Preprints Second Urban Environment Symposium - 13th Conference on Biometerology and Aerobiology, American Meterological Society Albuquerque: 140-143.

Matzarakis, A.; MaYer, H. (2000) - Atmospheric conditions and human thermal comfort in urban areas. $11^{\text {th }}$ Seminar on Environmental Protection, Environment and Health. 20-23, November 2000, Thessaloniki (Greece): 155-166.

MeIER, A. K. (1990/1991) - Strategic landscaping and air-conditioning savings: A literature review. Energy and Buildings 15-16: 479-486.

MiLls, G. (1999) - Urban climatology and urban design. 15 th . International Congress of Biometeorology \& International Conference on Urban Climatology, Macquarke University, Sydney (Australia): 1-6.

Mills, G. (2003) - The Meteorologically Utopian City Revisited. Proceedings of the Fifth International Conference on Urban Climate, Lödz, Polónia, vol. 2: 227-230.

Mitchell, K. M. (1998) - Hazards in changing cities. Applied Geography, 18 (1): 1-6.

Monteiro, A. (1993) - O clima urbano do Porto: Contribuição para a definição das estratégias de Planeamento e Ordenamento do Território. Faculdade de Letras da Universidade do Porto, Porto: 436.

Monteiro, A. (1997) - O clima urbano do Porto: Contribuição para a definição das estratégias de Planeamento e Ordenamento do Território. Fundação Calouste Gulbenkian e Junta Nacional de Investigação Científica e Tecnológica, Lisboa.

Monteiro, F. (2003) - Teoria e clima urbano, um projecto e seus caminhos. In C. A. Monteiro e F. Mendonça - Clima urbano. Editora Contexto, São Paulo: 9-67.

Moran, M. D.; Portelli, R. V. (1987) - Atmospheric transport and diffusion. Air Pollution. C. S. Corporation. Ontario (Canada): 117-127.

MorRis, C. J. G.; Simmonds, I. (2000) - Associations between varying magnitudes of the urban heat island and the synoptic climatology in Melbourne, Australia. International Journal of Climatology, 20: 1931-1954.

Neto, J. (2005) - Estudo da circulação atmosférica e Verão sobre a região de Lisboa. Interacção entre a brisa de mar, os efeitos de ilha urbana, a orografia e a presença do estuário. Dissertação de Mestrado em clima e ambiente atmosférico, área de Meteorologia, Clima e alterações climáticas. Universidade de Évora, Évora. 
Newman, P. W. G. (1999) - Sustainability and cities: extending the metabolism model. Landscape and Urban Planning, 44(4): 219-226.

Nikolopoulou, M.; Baker, N.; Steemers, K. (2001) - Thermal comfort in outdoor urban spaces: understanding the human parameter. Solar Energy, 70(3): 227-235.

Nikolopoulou, M.; Steemers, K. (2003) - Thermal comfort and psychological adaptation as a guide for desiging urban spaces. Energy and Buildings, 35:95-101.

OJo, O.; Adedokun, A. (1999) - Bringing designers and climatologists together: the nigerian experience. $15^{\text {th }}$. International Congress of Biometeorology \& International Conference on Urban Climatology, Macquarke University, Sydney (Australia): 1-6.

OKE, T. R. (1984a) - Towards a prescription for the greater use of climatic principles in settlement planning. Energy and Buildings, 7: 1-10.

OKE, T. R. (1984b) - Methods in Urban Climatology. Zürcher Geographische Schriften. Applied Climatology, 25th International Geographical Congress Symposium n. ${ }^{\circ}$ 18: Applied Geography Zurich, 19: 19-30.

OKE, T. R. (1987) - Boundary layer climates. Routledge, London.

OKe, T. R. (1988) - The urban energy balance. Progress in Physical Geography, 12(4): 471-508.

OKE, T. R. (1997) - Urban climates and global environmental change. In R. D. Thompson and E. Perry - Applied climatology. Routledge, London, part. 4: 273: 286.

OKE, T. R. (2004) - Initial Guidance to obtain representaive meteoerological observations at urban sites. WMO, Iinstruments and Observing Methods, Report n. ${ }^{\circ} 81$.

Olgyay, V. (1963) - Design with climate - a bioclimatic approach to architectural regionalism. Princeton University Press, New Jersey.

ORLANSKY, I. (1975) - Rational subdivision of scales for atmospheric processes. Bull. Amer. Met. Soc., 56: 527-530.

Paccione, M. (1990) - Urban problems. An applied Urban Analysis. Routledge, London.

Paccione, M. (2003) - Urban environmental quality and human wellbeing; a social geographical perspective. Landscape and Urban Planning, 65(1-2): 19-30.

PARsons, K. C. (1993) - Human thermal environments. Taylor \& Francis, London.

Partidério, M. R. (2001) - Indicadores de Qualidade do Ambiente Urbano. Direcção-Geral do Ordenamento do Território e do Desenvolvimento Urbano, Lisboa.

Patz, J. A.; Mcgeehin, M. A.; Bernard, S. M. K. L. E.; Epstein, P. R.; Grambsch, A.; Gubler, D. J.; Reiter, P.; Romieu, I.; Rose, J. B.; Samet, J. M.; Trtanj, J. (2000) - The potencial health impacts of climate variability and change for United States: executive summary of the report of the health sector of the U.S. National Assessment. Environmental Health Perspectives, 108 (4): $1-2$.

Pinho, O. S.; ORgaz, M. D. M (2000) - The urban heat island in a small city in coastal Portugal. International Journal of Biometeorology, 44: 198-203.

Pinho, P. (1995) - A propósito da qualidade do ambiente urbano: contributos para a crítica do Livro Verde da União Europeia. InforGeo, 9-10: 27-38.

Poeira, M. L.; Eloy, M. J.; Maymone, M. L.; Sousa, A. R. S. (2001) - Ambiente urbano em Portugal. Falta editor, Lisboa.

RAHAMimoff, A. (1984) - Residential cluster based on climate and energy considerations. Energy and Buildings, 7: 89-107. 
RATTI, C.; RAYDAN, D. et al. (2003) - Building form and environmental performance: archetypes, analysis and an arid climate. Energy and Buildings, 35: 49-59.

Rogers, C. (2004) - Carbon Dioxide, Climate Change and aeroallergens. In P. R. Epstein and C. ROGERS - Inside the greenhouse, the impacts of $\mathrm{CO} 2$ and climate change on public health in the inner city. Report from the center for health and the global environment. Harvard Medical School.

Rosenfeld, A. H.; Akbari, H.; Romm, J. J.; Pomerantz, M.; Taha, H. G. (1995) - Mitigation of urban heat islands: materials, utility programs, updates. Energy and Buildings, 22: 255-265.

Rosenfeld, A. H.; Akbari, H.; Romm, J. J.; Pomerantz, M. (1998) - Cool communities: strategies for heat island mitigation and smog reduction. Energy and Buildings, 28: 51-62.

RотAсH, M. W. (1999) - On the influence of the urban roughness sublayer on turbulence and dispersion. Atmospheric Environment, (33): 4001-4008.

Rubinstein, M.; Ganor, E.; OHRing, G. (1980) - Areal distribution of the disconfort index in Israel. International Journal of Biometeorology, 24(4): 315-322.

SAlgueiro, T. B. (2001) - Lisboa, periferia e centralidades. Celta, Lisboa.

SANTAMOURIS, M. (2001a) - On the built environment - the urban influence. In M. SANTAMOURIS (ed.) Energy and Climate in the Built Environment. James \& James Ltd, Londres: 3-18.

SANTAMouris, M. (2001b) - The energy impact of the urban environment. In M. SANTAMOuRIS (ed.) Energy and Climate in the Built Environment. James \& James Ltd, Londres: 97-109.

Saraiva, J. A. G. (1996) - Acção do vento e nível de conforto em espaços urbanos. A Cidade e o Clima. Direcção-Geral do Ordenamento do Território e do Desenvolvimento Urbano, Lisboa.

Scherer, D.; Fehrenbach, U.; Beha, E. D.; Parlow, E. (1999) - Improved concepts and methods in analysis and evaluation of the urban climate for optimizing urban planning processes. Atmospheric Environment, 33: 4185-4193.

SHEAFFER, J. D.; ReITER, E. R. (1988) - Urban climate effects of energy demand for space heating. Meteorology and Atmospheric Physics, 38(4): 202-214.

Spronken-Smith, R. A.; OKe, T. R.; Lowry, H. P. (2000) - Advection and the surface energy balance across an irrigated urban park. International Journal of Climatology, 20: 1033-1047.

Steemers, K. (2003a) - Cities, energy and comfort: a PLEA 2000 review. Energy and Buildings, 35: $1-2$.

STEEMERS, K. (2003b) - Energy and the city: density, buildings and transport. Energy and Buildings, 35(1): 3-14.

Stull, R. B. (1988) - An introduction to boundary layer meteoreology. Kluwer Academic Publishers, Vancouver (Canada).

SvENSSON, M. K.; EliASSON, I. (2002) - Diurnal air temperature in built-up areas in relation to urban planning. In Svensson, M. K. (ed.) - Urban climate in relation to land use, planning and comfort. Goteborg University - Department of Earth Sciences, Goteborg.

Szokolay, S. V. (1997) - Bioclimatic Architecture and Solar Energy. In A. Auliciems (ed.) - Advances in Bioclimatology - 5. Human Bioclimatology. Springer, Queensland (Australia): 111-132.

TAEsLER, R. (1990-91) - Climate and building energy management. Energy and Building, 15-16: 599-608.

Thamm, H-P.; Gossmann, H.; Roeckle, R.; Richter, C. J.; Todt, T. (1999) - Conflicting interests of planners, politicians and scientists in urban climatology as examplified by the city of Frei- 
burg, Germany. 15 th International Congress of Biometeorology \& International Conference on Urban Climatology, Macquarie University, Sidney (Australia): 1-7.

Thomas, L.; Cousins, W. (1996) - A new compact city form: concepts and practice. In M. JENKs; E. Burton and K. WiLiams (eds.) - The Compact City, a sustainable urban form? E \& F N Spon, London: 328-338.

VDI (1998)-Environmental meteorology, methods for the human-biometeorological evaluation of climate and air quality for urban and regional planning at regional level. VDI-Verlag, Dusseldorf.

Vieira, H.; Vasconcelos, J. (2003) - Urban Morphology Characterisation to Include in a GIS for Climatic Purposes in Lisbon. Discussion of Two Different Methods. Proceedings of the Fifth International Conference on Urban Climate. Lødz, vol. 2: 417-420.

WanNer, H. (1984) - Methods in applied topoclimatology. Zürcher Geographische Schriften. Applied Climatology, 25th International Geographical Congress Symposium n. ${ }^{\circ}$ 18: Applied Geography Zurich, 19: 19-30;1-13.

Wanner, H.; Filliger, P. (1989) - Orographic Influence on Urban Climate. Weather and Climate, 9: $22-28$.

Welbank (1996) - The search for a sustainable urban form. In M. JENKs; E. BuRTon and K. Wiliams (eds.) - The Compact City, a sustainable urban form? E \& F N Spon, London, 74- 82.

Whitford, V.; EnNos, A. R.; HANDley, J. F. (2001) - City form and natural process - indicators for the ecological performance of urban areas and their application to Merseyside, UK. Landscape and Urban Planning, 57(2): 91-103.

WILKs, D. (1995) - Statistical methods in the atmospheric sciences. Academic Press, San Diego: 467 p.

YANNAS, S. (2001) - Toward more sustainable cities. Solar Energy, 70 (3): 281-294.

Yoshino, M. M. (1975) - Climate in a small area. An introduction to local Meteorology. University of Tokyo Press, Tokyo. 